\title{
A construção de uma horta vertical como estratégia de educação alimentar e nutricional para idosos: uma parceria entre Programa de Educação Tutorial em Nutrição e Programa de Educação Tutorial em Engenharia Agrícola e Ambiental
}

Leticia Soares Bueno da Silva, Juliana Farias de Novaes, Carolina de Almeida, Bruna Amorim Teixeira, Jéssica Rodrigues de Morais, Naycelle Aparecida Gomes Ribeiro

\section{Resumo}

O consumo aumentado de frutas e hortaliças contribui para a redução do risco de Doenças Crônicas não Transmissíveis (DCNT), especialmente pela maior oferta de vitaminas, minerais, antioxidantes e fibras alimentares, advindos desses tipos de alimentos. Nesse sentido, a avaliação do consumo pelos idosos é fundamental uma vez que representam um grupo vulnerável às DCNT. Como alternativa para aumentar o consumo de hortaliças, pode-se implantar hortas verticais, que além de proporcionar alimentos orgânicos e diversificados, permitem a reciclagem de materiais, aproveitamento de espaço e são de baixo custo e de fácil acesso, auxiliando na promoção de uma melhor qualidade de vida. O objetivo deste estudo foi incentivar o maior consumo de hortaliças por idosos do Programa Municipal da Terceira Idade (PMTI) de Viçosa-MG, através da construção de uma horta vertical. Foi desenvolvida uma oficina por integrantes do Programa de Educação Tutorial em Nutrição (PET-NUT) em parceria com o Programa de Educação Tutorial em Engenharia Agrícola e Ambiental (PET-EAA) da Universidade Federal de Viçosa (UFV), Minas Gerais (MG), com intuito de capacitar os idosos do PMTI a construir uma horta vertical com garrafas pets. Os participantes foram idosos com 60 anos ou mais, de ambos os sexos. Os membros do PET-EAA demonstraram como deve ser o preparo da terra, o corte da garrafa pet e como plantar as mudas. As hortaliças utilizadas foram couve, alface, agrião, cebolinha, salsinha e almeirão. O PET-NUT abordou os benefícios do consumo destas hortaliças para a saúde. Ao final da oficina, foram distribuídas mudas de hortaliças para que cada participante reproduzisse a atividade em sua residência. Durante a atividade, os idosos foram participativos com perguntas e sugestões, demonstrando interesse em construir a própria horta. Alguns afirmaram já possuir uma horta vertical, já que moravam em apartamento e não tinham espaço para uma horta tradicional, e puderam aprimorar os conhecimentos por meio desta oficina. Conclui-se que a construção da horta vertical foi uma boa estratégia de educação alimentar e nutricional, sendo uma forma dinâmica de estimular o consumo diário de hortaliças.

Descritores: Horta vertical; Educação alimentar e Nutricional; Hortaliças. 